GALHARDO, J.A., MENEZES, D.C. e OLIVEIRA, N.G. Influenza equina: revisão de literatura.

PUBVET, Londrina, V. 8, N. 14, Ed. 263, Art. 1745, Julho, 2014.

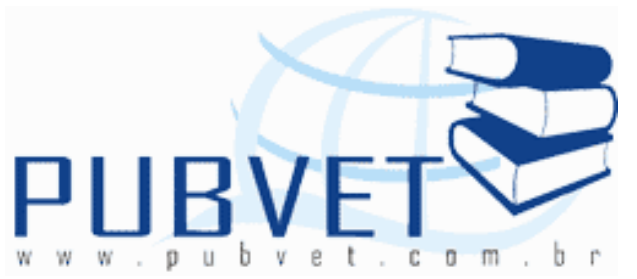

PUBVET, Publicações em Medicina Veterinária e Zootecnia.

\title{
Influenza equina: revisão de literatura
}

Juliana Arena Galhardo수 , Daniely Coelho de Menezes², Nathalia Guedes de Oliveira ${ }^{2}$

${ }^{1}$ Docente do curso de Medicina Veterinária, Faculdade de Medicina Veterinária e Zootecnia - Universidade Federal de Mato Grosso do Sul. E-mail: juliana.galhardo@ufms.br

${ }^{2}$ Acadêmica do curso de Medicina Veterinária, Faculdade de Medicina Veterinária e Zootecnia - Universidade Federal de Mato Grosso do Sul

\section{Resumo}

O vírus da influenza equina (EIV) é considerado um dos principais agentes infecciosos causadores de surtos respiratórios em equídeos no Brasil e no mundo. O EIV é classificado em dois subtipos. O subtipo H3N8 encontra-se amplamente disseminado na população equina mundial e o subtipo H7N7, apesar de ser eventualmente detectado por métodos sorológicos, é considerado extinto ou circulante em baixos níveis de prevalência. A enfermidade apresenta período de incubação curto, em torno de 48 horas, e a recuperação de até três semanas. A gripe equina é caracterizada principalmente por morbidade elevada e baixa mortalidade e os sinais clínicos variam de leves a severos, dependendo do estado imunitário do animal, podendo ocorrer o agravamento do quadro devido a infecções bacterianas secundárias. O diagnóstico é baseado nas características clínicas e 
GALHARDO, J.A., MENEZES, D.C. e OLIVEIRA, N.G. Influenza equina: revisão de literatura. PUBVET, Londrina, V. 8, N. 14, Ed. 263, Art. 1745, Julho, 2014.

epidemiológicas da afecção. É importante o diagnóstico diferencial principalmente para Rodococcus equi e Streptococcus equi. A terapia básica é de suporte, incluindo o isolamento dos animais sintomáticos. Como medidas profiláticas são utilizados métodos de manejo sanitário associados à vacinação.

Palavras-chave: equídeos, gripe, Influenzavirus

\section{Equine influenza: literature review}

\section{Abstract}

Equine influenzavirus (EIV) is considered one of the major infectious agents causing respiratory outbreaks in horses in Brazil and worldwide. EIV is classified into two subtypes, H3N8 is widespread in horse population and subtype H7N7, despite being possibly detected by serological methods, is considered extinct or circulating at low levels of prevalence. The disease presents short incubation period, about 48 hours, and recovery of up to three weeks. Equine influenza is mainly characterized by high morbidity and low mortality and clinical signs vary from mild to severe, depending on the immune status of the animal, which may occur due to worsening of secondary bacterial infections. Diagnosis is based on clinical and epidemiological characteristics of the disease. It is important for the differential diagnosis mainly Rodococcus equi and Streptococcus equi. Basic therapy is supportive, including the isolation of symptomatic animals. Prophylactic measures are used as methods of health management associated with vaccination.

Keywords: equids, flu, Influenzavirus

\section{Introdução}

A equideocultura é uma atividade que ocupa importante posição na agropecuária e, consequentemente, na economia brasileira. O rebanho equino brasileiro é o quarto maior rebanho do mundo. Esta importância na economia, além do valor emocional agregado aos animais pelos seus proprietários, levou 
GALHARDO, J.A., MENEZES, D.C. e OLIVEIRA, N.G. Influenza equina: revisão de literatura. PUBVET, Londrina, V. 8, N. 14, Ed. 263, Art. 1745, Julho, 2014.

ao aumento do interesse em pesquisas sobre aspectos na sanidade destes animais. Entre as enfermidades que acometem estes animais destaca-se a influenza equina.

A influenza equina, ou gripe equina, é uma enfermidade que afeta as vias aéreas superiores de equídeos, considerada endêmica em diversos países e caracterizada por alta morbidade e baixa mortalidade. É altamente contagiosa e a ocorrência de surtos está relacionada a fatores como idade, estado imunitário, coinfecções, estresse de manejo, aglomerações, baixas temperaturas e falhas vacinais, causando prejuízos sobretudo em animais atletas e animais de exposição, principalmente na primavera e outono (Mori et al., 2012).

\section{Desenvolvimento}

\section{Etiologia}

A doença é causada pelo Vírus da Influenza Equina (Equine Influenzavirus - EIV), pertencente à Família Orthomyxoviridade, Gênero Influenzavirus A (ICTV, 2012). A partícula viral possui envelope lipídico derivado da célula do hospedeiro, possui cerca de 80 a $120 \mathrm{~nm}$ de diâmetro e o genoma é constituído por uma fita simples de RNA de sentido negativo dividida em oito segmentos. Um vírion típico é composto pelas seguintes estruturas: hemaglutinina (HA), neuraminidase (NA) e proteína M2 (canal iônico) como proteínas integrais imersas no envelope; proteína da matriz (M1); proteínas PA, PB1 e PB2 que compõem o complexo polimerase associadas ao RNA viral (vRNA) e; nuceloproteína viral (NP) que envolve os oito segmentos do RNA viral formando oito complexos ribonucleoproteína (Maclachlan e Dubovi, 2011; Landolt, Townsend e Lunn, 2007).

Os influenzavírus são classificados em subtipos, de acordo com a reatividade antigênica das glicoproteínas HA (H1 a H16) e NA (N1 a N9), responsáveis pela adsorção viral à célula e pela saída de novas partículas, respectivamente (Fouchier et al., 2005). Em equídeos são descritos apenas 
GALHARDO, J.A., MENEZES, D.C. e OLIVEIRA, N.G. Influenza equina: revisão de literatura. PUBVET, Londrina, V. 8, N. 14, Ed. 263, Art. 1745, Julho, 2014.

dois subtipos, H3N8 e H7N7, e atualmente relata-se apenas a ocorrência do subtipo H3N8 em diversas regiões do mundo, com exceção de Nova Zelândia e Islândia, consideradas áreas livres de influenza equina (OIE, 2012a).

Além do surto que levou à descoberta do EIV em 1963, outros surtos envolvendo transmissão de aves para equídeos foram reportados. O surto ocorrido em 1980 na China envolveu a transmissão de uma variante do subtipo H3N8 entre aves e cavalos e foi registrada letalidade próxima a 10\%. Em outros dois surtos ocorridos na China, em 1989 e 1990, também foi isolado o subtipo H3N8 altamente patogênico. Através de provas moleculares, identificou-se que este vírus teve origem aviária e que ambos os isolados eram genomicamente e antigenicamente distintos da amostra protótipo (A/equine/Miami/63). O surto mais recentemente reportado ocorreu em 2010 no Egito, com a transmissão do subtipo H5N1 altamente patogênico de aves para muares e promoveu sinais clínicos moderados (Elton e Bryant, 2011; Adbdel-Moneim et al., 2010; Webster e Thomas 1993; Guo et al., 1992; Waddell, Teigland e Sigel, 1963).

O subtipo H3N8 de equídeos foi detectado em casos de doença clínica em cães nos Estados Unidos, Reino Unido e Austrália, confirmando o salto interespécies entre equinos e cães (Kirkland et al., 2010; Daly et al, 2008; Newton et al., 2007, Crawford et al., 2005) porém não foi confirmada a infecção de equinos a partir de cães infectados (Yamanaka et al., 2012).

\section{Epidemiologia}

Equinos de todas as idades são suscetíveis à infecção pelo EIV, principalmente aqueles que não tenham sofrido exposição prévia ao agente ou que não tenham sido vacinados. No entanto, a enfermidade tem maior prevalência em animais com idade inferior a dois anos. Além disso, a enfermidade ocorre com maior frequência em animais que são transportados por longas distâncias ou confinados em locais pouco ventilados. $O$ transporte e a aglomeração dos animais em locais escuros, com pouca ventilação, favorecem a ocorrência da enfermidade (Mori et al., 2012). 
GALHARDO, J.A., MENEZES, D.C. e OLIVEIRA, N.G. Influenza equina: revisão de literatura. PUBVET, Londrina, V. 8, N. 14, Ed. 263, Art. 1745, Julho, 2014.

A morbidade pode chegar a $100 \%$ em populações suscetíveis e as taxas de mortalidade costumam ser baixas, exceto em animais imunossuprimidos, recém-nascidos e em muares, aparentemente mais suscetíveis ao EIV que cavalos. Esses podem desenvolver o quadro subclínico e devem ser considerados importantes fontes de infecção para os demais equídeos. A transmissão se dá por aerossóis, secreções, água e alimento contaminados e por contato direto. Animais naturalmente infectados possuem melhor resposta imunológica frente a novas infecções comparados aos imunizados artificialmente. A primoinfecção natural pode conferir boa imunidade por até seis meses e induzir imunidade parcial por até um ano (Hannant, Mumford e Jessett, 1988).

O período de incubação do EIV é curto, em torno de 48 horas e a replicação viral ocorre em apenas 24 horas. Em três a cinco dias o epitélio inicia a regeneração e, em animais imunocompetentes, a recuperação completa ocorre em até três semanas (Kuiken et al., 2012; Elton e Briant, 2011; Myers e Wilson, 2006).

\section{Patogenia e sinais clínicos}

Após a entrada do vírus pela via aerógina, ocorre a replicação principalmente no epitélio do trato respiratório superior, produzindo sinais respiratórios que variam em severidade e duração de acordo com a virulência da amostra viral, o manejo, as condições ambientais e as defesas do hospedeiro (Wilson, 2006).

A replicação e liberação de novos vírions induzem à morte celular, apoptose vírus-induzidos e consequente descamação do epitélio respiratório, especialmente de traqueia e brônquios, em apenas 24 horas após o estabelecimento dos sinais clínicos. A superfície epitélio dessas regiões tornase descamada e sem cílios. Consequentemente, alguns receptores são estimulados, causando hipersecreções das glândulas serosas presentes na submucosa, prejudicando a função de proteção do epitélio muco-ciliar. Essas alterações permitem a invasão por patógenos oportunistas, como o 
GALHARDO, J.A., MENEZES, D.C. e OLIVEIRA, N.G. Influenza equina: revisão de literatura. PUBVET, Londrina, V. 8, N. 14, Ed. 263, Art. 1745, Julho, 2014.

Rhodococcus equi e Streptococcus equi e, consequentemente, a complicação da enfermidade (Tabela 1). Estas lesões podem favorecer a instalação de infecção bacteriana secundária, agravando o quadro respiratório e predispondo a broncopneumonia bacteriana. Em três a cinco dias o epitélio inicia a regeneração e, em animais imunocompetentes, a recuperação completa ocorre em até três semanas (Figura 1) (Kuiken et al., 2012; Mori et al., 2012; Elton e Briant, 2011; Myers e Wilson, 2006).

Os sinais clínicos incluem febre em torno de $41^{\circ} \mathrm{C}$, com um pico em 48 horas pós-infecção e um novo pico febril após cinco dias. Tosse paroxística e descarga nasal serosa, podendo evoluir para descarga muco purulenta, linfadenopatia, taquipnéia, anorexia, perda de peso e, em animais imunocomprometidos, complicações como miocardite, miosite ou mesmo encefalite podem se desenvolver. A infecção pelo EIV pode em alguns casos predispor a doença pulmonar obstrutiva crônica e a hemorragia pulmonar induzida por exercícios. A recuperação está diretamente relacionada com o grau de contaminação secundária e com o tipo de repouso ao qual o animal é submetido durante a enfermidade (Kuiken et al., 2012; Mori et al., 2012; OIE, 2012b; Elton e Briant, 2011; Maclachlan e Dubovi, 2011; Landolt, Townsend e Lunn, 2007). 
GALHARDO, J.A., MENEZES, D.C. e OLIVEIRA, N.G. Influenza equina: revisão de literatura.

PUBVET, Londrina, V. 8, N. 14, Ed. 263, Art. 1745, Julho, 2014.

Tabela 1- Diagnóstico diferencial das principais doenças respiratórias de origem infecciosas de equídeos

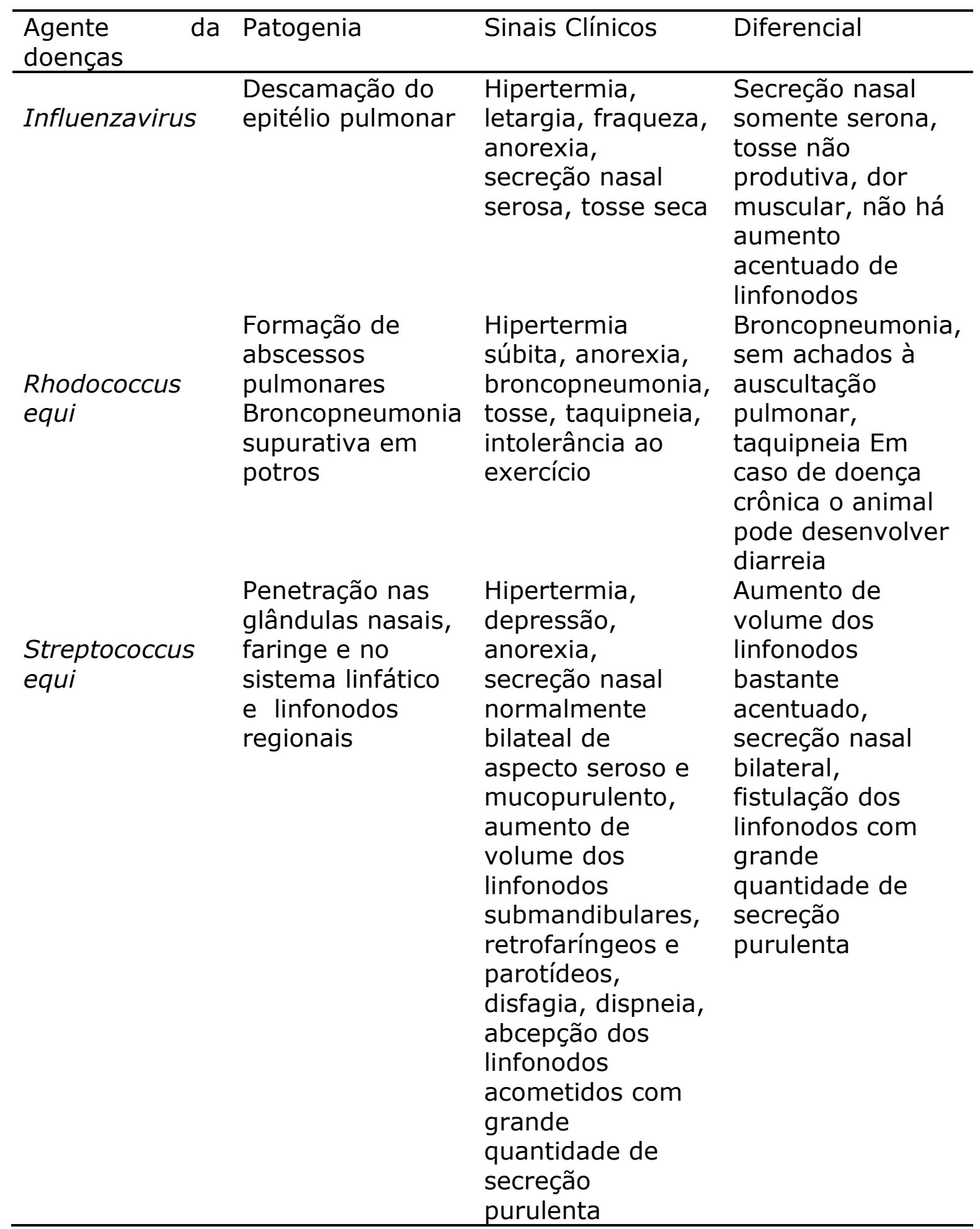


GALHARDO, J.A., MENEZES, D.C. e OLIVEIRA, N.G. Influenza equina: revisão de literatura. PUBVET, Londrina, V. 8, N. 14, Ed. 263, Art. 1745, Julho, 2014.

\section{Diagnóstico}

O diagnóstico clínico baseia-se nos sinais clínicos associados ao histórico dos animais e evidências epidemiológicas. Testes laboratoriais são recomendados para diferenciar influenza equina de infecções por outros vírus como herpesvírus equino tipo 1 e tipo 4, vírus da arterite equina e outros agentes. Técnicas como isolamento viral, ensaio imunoenzimático (ELISA), imunofluorescência direta, reação em cadeia pela polimerase com transcriptase reversa (RT-PCR) ou PCR em tempo real são recomendadas para determinar o agente e são úteis na caracterização das variantes e estirpes circulantes. Considerando o rápido curso da doença clínica, estas técnicas somente são válidas se as amostras biológicas forem obtidas nas primeiras 48 após a infecção, após este período a sensibilidade é bastante reduzida (OIE, 2012a; Maclachlan e Dubovi, 2011; Lu et al., 2009; Quinlivan et al., 2004).

Testes sorológicos como inibição de hemaglutinação, neutralização viral, hemólise radial simples e ELISA podem ser utilizados para determinar a eficácia vacinal ou para fins de vigilância epidemiológica de rebanhos. Um importante interferente em vigilância de rebanhos é a incapacidade destes testes de diferenciar animais vacinados de não vacinados, sendo necessário realizar testes pareados para comparação de títulos, o que torna a vigilância inviável em alguns casos (OIE, 2012a). 


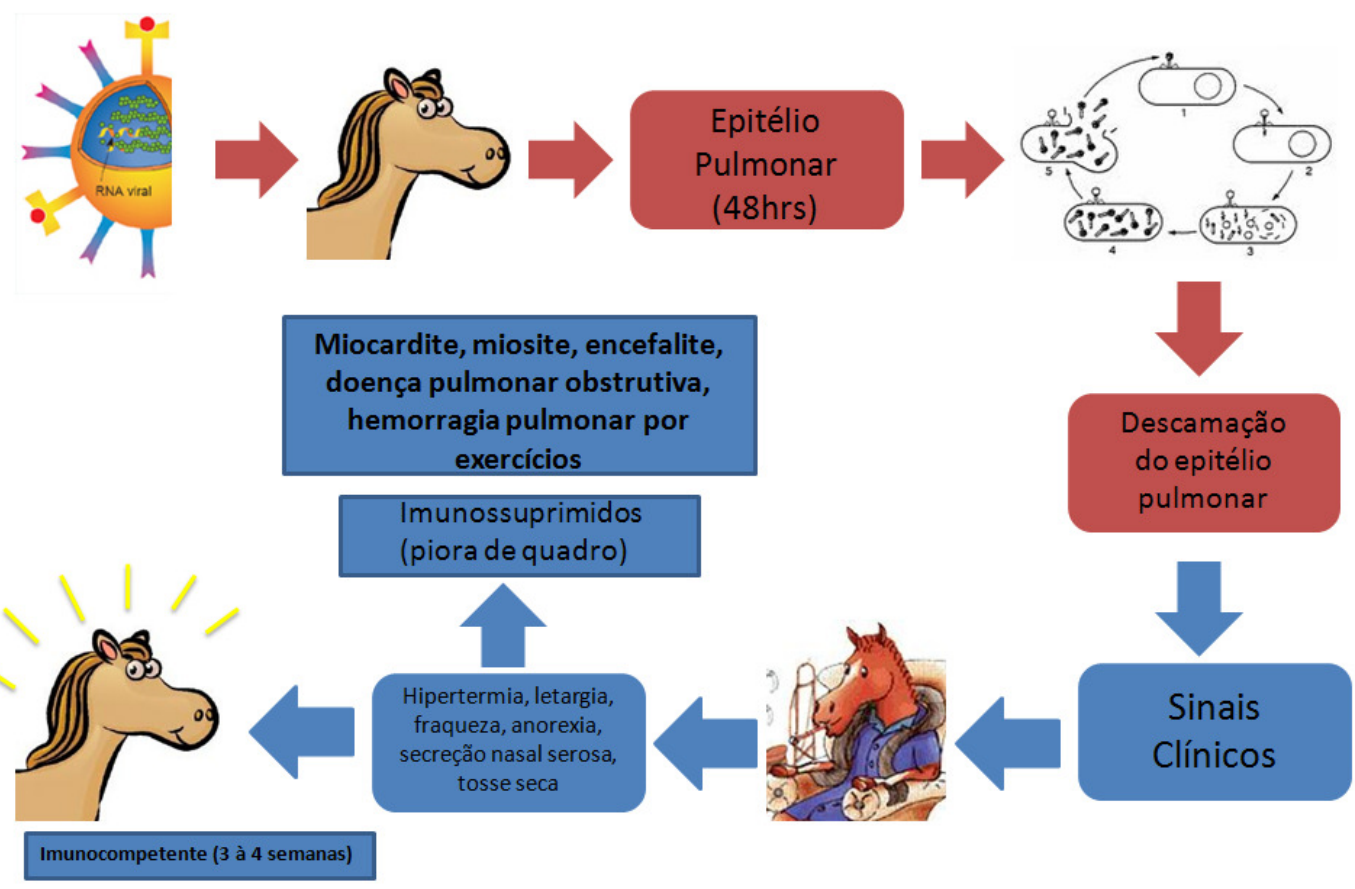

Figura 1 - Desenho esquemático da patogenia e sinais clínicos da influenza equina.

Ao hemograma os equinos podem inicialmente apresentar linfopenia seguida de monocitose, (Wintzer et al.,1990). O exame endoscópico da faringe, laringe e traqueia pode revelar indícios de inflamação e infecções secundárias. Amostras de lavado traqueal podem ser submetidas a cultivo e citologia, principalmente nestes casos. O diagnóstico definitivo pode ser obtido através do isolamento do vírus em swabs nasofaríngeos coletados na fase aguda da infecção, nas primeiras 24 horas. Pode-se fazer um diagnóstico retrospectivo através da observação do aumento de quatro vezes ou mais no título de anticorpos em amostras de soro pareadas, coletadas com um intervalo de 10 a 14 dias. (Mori et al., 2012; OIE, 2012b; Kuiken et al., 2012; Elton e Briant, 2011; Maclachlan e Dubovi, 2011; Landolt, Townsend e Lunn, 2007).

\section{Tratamento}

Deve ser feito o isolamento imediato dos animais doentes para reduzir o 
GALHARDO, J.A., MENEZES, D.C. e OLIVEIRA, N.G. Influenza equina: revisão de literatura. PUBVET, Londrina, V. 8, N. 14, Ed. 263, Art. 1745, Julho, 2014.

risco de transmissão para outros equídeos e o tratamento é sintomático e de apoio. Equinos infectados não devem ser submetidos a estresse indevido e desnecessário, mantidos em repouso total, uma vez que o repouso diminui a gravidade dos sinais clínicos, minimiza a excreção viral e encurta o período de recuperação. Recomenda-se uma semana de repouso para cada dia de febre, com retorno gradativo às atividades. (Mori et al., 2012)

É comum a ocorrência de complicações secundárias e sequelas da influenza equina em animais estressados ou indevidamente tratados, de forma que é fundamental enfatizar a importância dos cuidados de apoio e o repouso adequado. Os animais que sofrem infecções graves podem ficar fora de forma para competições até três meses após a infecção. Equinos infectados e inapetentes podem precisar de estímulo para comer. Recomenda-se oferecer uma variedade de alimento palatável e de boa qualidade para garantir o consumo adequado de nutrientes. Pode-se indicar o uso de drogas antiinflamatórias não esteroidais para diminuir a febre, eliminar a mialgia e melhorar o apetite. A escolha do antibiótico para tratamento de infecção bacteriana secundária deve se basear nos resultados de cultura de lavado traqueal (Mori et al., 2012; OIE, 2012b; Kuiken et al., 2012; Elton e Briant, 2011; Maclachlan e Dubovi, 2011; Landolt, Townsend e Lunn, 2007)

\section{Profilaxia}

A vacinação anual ou semestral de todos os animais é o método mais indicado de prevenção. É importante garantir um bom fornecimento de anticorpos no colostro para proteger os potros. Éguas prenhes podem eventualmente ser estrategicamente vacinadas na fase final de gestação, e em potros, a vacinação deve ser iniciada aos quatro meses de idade, potros sem imunidade colostral deverão ser vacinados mais cedo em situações de alto risco. Somente após o reforço vacinal será obtida a imunidade ideal (Mori et al., 2012; OIE, 2012ab; Maclachlan e Dubovi, 2011).

Equinos jovens devem ser vacinados a cada seis meses e, se participarem de competições regularmente, recomenda-se a vacinação em 
GALHARDO, J.A., MENEZES, D.C. e OLIVEIRA, N.G. Influenza equina: revisão de literatura. PUBVET, Londrina, V. 8, N. 14, Ed. 263, Art. 1745, Julho, 2014.

intervalos de três a quatro meses para oferecer um nível ótimo de proteção. Não se recomenda a vacinação de equinos contra influenza por um período de sete a 10 dias antes de eventos ou provas. No caso de vacinas importadas, recomenda- se que sejam aplicadas em duas a três doses com intervalos de um a três meses na primeira vez, e a seguir aplicadas uma só dose ao ano, ou então duas doses com intervalo de três meses, conforme Tabela 2 . As vacinas nacionais devem ser repetidas cada seis meses e o ideal é que os equinos sejam monitorados através de exames sorológicos para avaliar a resposta vacinal (Mori et al., 2012; OIE, 2012ab; Maclachlan e Dubovi, 2011).

Dada a dificuldade de diagnóstico precoce e o alto custo, não é recomendo o uso de antivirais e a terapia de suporte é a mais indicada. Ações de manejo sanitário devem ser adotadas como o isolamento de animais doentes, evitar cochos e bebedouros compartilhados, evitar estresse físico e ambiental e utilizar equipamentos individuais. O alojamento e os veículos de transporte devem ser totalmente desinfetados antes da reutilização por animais sadios. O trânsito entre instalações e propriedades com animais infectados e animais sadios deve ser evitado até a resolução dos casos. O vírus é muito suscetível à luz solar e a desinfetantes, tal qual hipoclorito de sódio a $2,0 \%$ e formol a $8,0 \%$, não sobrevivendo no ambiente por longos períodos a menos que fique protegido por soluções proteináceas como secreções nasais. As medidas profiláticas para influenza equina requerem praticas de manejo e vacinação para serem bem sucedidas (Mori et al., 2012; OIE, 2012ab; Maclachlan e Dubovi, 2011). 
GALHARDO, J.A., MENEZES, D.C. e OLIVEIRA, N.G. Influenza equina: revisão de literatura. PUBVET, Londrina, V. 8, N. 14, Ed. 263, Art. 1745, Julho, 2014.

Tabela 2 - Calendário de vacinação para influenza equina

\begin{tabular}{|c|c|c|c|c|c|}
\hline $\begin{array}{l}\text { Cavalo } \\
\text { adulto } \\
\text { previamente } \\
\text { vacinado }\end{array}$ & $\begin{array}{l}\text { Cavalo } \\
\text { adulto } \\
\text { não } \\
\text { vacinado }\end{array}$ & $\begin{array}{l}\text { Égua prenhe } \\
\text { previamente } \\
\text { vacinada }\end{array}$ & $\begin{array}{l}\text { Égua } \\
\text { prenhe } \\
\text { não } \\
\text { vacinada }\end{array}$ & $\begin{array}{l}\text { Potro de } \\
\text { mãe } \\
\text { vacinada } \\
\text { no pré } \\
\text { parto }\end{array}$ & $\begin{array}{l}\text { Potro de mãe } \\
\text { não vacinada } \\
\text { no pré parto } \\
\text { ou histórico } \\
\text { desconhecido }\end{array}$ \\
\hline $\begin{array}{l}\text { Uma dose ao } \\
\text { ano ou duas } \\
\text { doses com } \\
\text { intervalo de } \\
\text { três meses }\end{array}$ & $\begin{array}{l}\text { Três } \\
\text { doses } \\
\text { com } \\
\text { quatro } \\
\text { semanas } \\
\text { de } \\
\text { intervalo } \\
\text { entre } \\
\text { cada dose }\end{array}$ & $\begin{array}{l}\text { Uma dose a } \\
\text { quatro } \\
\text { semanas do } \\
\text { parto com } \\
\text { vacina de } \\
\text { vírus inativo }\end{array}$ & $\begin{array}{l}\text { Uma dose } \\
\text { à quatro } \\
\text { semanas } \\
\text { do parto } \\
\text { com } \\
\text { vacina de } \\
\text { vírus } \\
\text { inativo }\end{array}$ & $\begin{array}{l}\text { Três } \\
\text { doses } \\
\text { com } \\
\text { quatro } \\
\text { semanas } \\
\text { de } \\
\text { intervalo } \\
\text { entre } \\
\text { cada } \\
\text { dose, } \\
\text { iniciando } \\
\text { a } 1 \text { a dose } \\
\text { no } \\
\text { terceiro } \\
\text { mês de } \\
\text { idade }\end{array}$ & $\begin{array}{l}\text { Três doses com } \\
\text { quatro } \\
\text { semanas de } \\
\text { intervalo entre } \\
\text { cada dose, } \\
\text { iniciando a } 1^{\text {a }} \\
\text { dose no } \\
\text { terceiro mês de } \\
\text { idade }\end{array}$ \\
\hline
\end{tabular}

\section{Considerações Finais}

No Brasil a influenza equina é uma das principais causas de doença respiratória em equinos e os recentes focos ocorridos em 2012 em todas as regiões do país evidenciam que a doença circula em todo o território nacional. As medidas propostas pelo Programa Nacional de Sanidade dos Equídeos (PNSE) são voltadas ao controle de anemia infecciosa equina e mormo, com determinações incipientes frente a influenza equina (Brasil, 2008). As recomendações de medidas sanitárias para controle da doença são anteriores ao PNSE (Brasil, 2001), assim como as legislações complementares frente a ações de fiscalização em exposições, rodeios e demais eventos (Brasil, 2002; Brasil, 1994; Brasil, 1993).

Apenas o diagnóstico clínico é realizado rotineiramente e as políticas de saúde animal não contemplam a realização de exames laboratoriais para detecção e confirmação das estirpes virais circulantes no país, sendo apenas realizado a termo de pesquisa nas Universidades brasileiras. Desta forma, 
GALHARDO, J.A., MENEZES, D.C. e OLIVEIRA, N.G. Influenza equina: revisão de literatura. PUBVET, Londrina, V. 8, N. 14, Ed. 263, Art. 1745, Julho, 2014.

maior importância deveria ser dada ao diagnóstico e prevenção desta enfermidade, que pode acarretar prejuízos devido ao tratamento de infecções bacterianas secundárias, impedimento de trânsito e debilidade dos animais. Cabe aos gestores públicos e à iniciativa privada a elaboração de políticas de profilaxia e controle baseadas em diagnóstico laboratorial e aplicadas às diversas realidades do Brasil.

\section{Literatura Citada}

BRASIL. Ministério da Agricultura, Pecuária e Abastecimento. Portaria no 108 de 17 de março de 1993. Aprovar as Normas anexas à presente Portaria, a serem observadas em todo o Território Nacional para a realização de exposições e feiras agropecuárias, leilões de animais e para a formação de Colégio de Jurados das Associações encarregadas da execução dos Serviços de Registro Genealógico. Diário Oficial da União, Brasília-DF, 18 mar. 1993, Seção 1, p.3266.

BRASIL. Ministério da Agricultura, Pecuária, do Abastecimento e Reforma Agrária. Departamento de Defesa Animal. Portaria no 162 de 18 de outubro de 1994. Aprovar as Normas complementares anexas à presente Portaria, baixadas pelo Departamento de Defesa Animal, que versam sobre a Fiscalização e o Controle Zoossanitário das Exposições, Feiras, Leilões e outras aglomerações de animais, em todo território Nacional. Diário Oficial da União, Brasília-DF, 21 out. 1994. Seção1, p. 15934.

BRASIL. Ministério da Agricultura, Pecuária e Abastecimento. Instrução de Serviço do Departamento de Defesa Animal n 17 de 16 de novembro de 2001. Determinação da adoção de medidas sanitárias em razão da ocorrência de influenza (gripe) equina. Diário Oficial da União, Brasília-DF, 18 nov. 2001. Disponível em:

http://www3.servicos.ms.gov.br/iagro_ged/pdf/102_GED.pdf. Acesso em: 05 nov. 2012.

BRASIL. Lei no 10.519 de 17 de julho de 2002. Dispõe sobre a promoção e a fiscalização da defesa sanitária animal quando da realização de rodeio e dá outras providências. Diário Oficial da União, Brasília-DF, 18 jul. 2002. Seção 1, p.1.

BRASIL, Ministério da Agricultura, Pecuária e Abastecimento. Instrução Normativa $n^{\circ} 17$ de 8 de maio de 2008. Institui o Programa Nacional de Sanidade dos Equídeos - PNSE, no âmbito do Ministério da Agricultura, Pecuária e Abastecimento. Diário Oficial da União, Brasília-DF, 09 mai. 2008. Seção 1, Página 27.

CRAWFORD, P. C.; DUBOVI, E. J.; CASTLEMAN, W. L.; STEPHENSON, I.; GIBBS, E. P.; CHEN, L.; SMITH, C.; HILL, R. C.; FERRO, P.; POMPEY, J.; BRIGHT, R. A.; MEDINA, M. J.; JOHNSON, C. M.; OLSEN, C. W.; COX, N. J.; KLIMOV, A. I.; KATZ, J. M.; DONIS, R. O. Transmission of equine influenza virus to dogs. Science, v.310, p.482-485, 2005.

DALY, J. M.; BLUNDEN, A. S.; MACRAE, S.; MILLER, J.; BOWMAN, S. J.; KOLODZIEJEK, J.; NOWOTNY, N.; SMITH, K. C. Transmission of equine influenza virus to English foxhounds.

Emerging Infectious Diseases, v.14, p.461-464, 2008.

DIEL, D. G.; Almeida, S. R.; Weiblen, R.; Frandoloso, R.; Anziliero,D.; Kreutz, L. C.; Groff, F. H. S.; Flores, E. F. Prevalência de anticorpos contra o vírus da influenza da arterite viral e herpesvirus equinos do Estado do Rio Grande do Sul, Brasil. Revista Ciência Rural, Santa Maria, v.36, n.5, p.1467-1673, 2006. 
ELTON, D.; BRIANT, N. Facing the threat of equine influenza. Equine Veterinary Journal, V.43, n.3, p. 250-258, 2011.

FOUCHIER, R.A., MUNSTER, V., WALLENSTEN, A., BESTEBROER, T.M., HERFST, S., SMITH, D., RIMMELZWAAN, G.F., OLSEN, B., OSTERHAUS, A.D. Characterization of a novel influenza A virus hemagglutinin subtype ( $\mathrm{H} 16)$ obtained from black-headed gulls. Journal of Virology, v.79, p.2814-2822, 2005.

GUO, Y. et al. Characterization of a new avian-like influenza A virus from horses in China. Virology, v. 188, p. 245-255, 1992.

HANNANT, D.; MUMFORD, J. A.; JESSETT, D. M. Duration of circulating antibody and immunity following infection with equine influenza virus. Veterinary Record, v.122, p.125-128, 1988.

ICTV - INTERNATIONAL COMMITTEE ON TAXONOMY OF VIRUS, 2012. Disponível em: http://ictvonline.org/. Acesso em: 11 out. 2012.

KIRKLAND, P. D.; FINLAISON, D. S.; CRISPE, E.; HURT, A. C. Influenza virus transmission from horses to dogs, Australia. Emerging Infectious Diseases, v.16, p.699-702, 2010.

KUIKEN, T.; RITEAU, B.; FOUCHIER, R. A. M.; RIMMELZWAAN, G. F. Pathogenesis of influenza virus infections: the good, the bad and the ugly. Current Opinion in Virology, n.2, p.276286, 2012.

LANDOLT, G. A.; TOWNSEND, H. G. G.; LUNN, P. D. Equine Influenza Infection. In: SELLON, D. C.; LONG, M. T. Equine Infectious Diseases, Saunders-Elsevier, 2007. p.124.

LU, Z.; CHAMBERS, T. M.; BOLIAR, S.; BRANSCUM, A. J.; STURGILL, T. L.; TIMONEY, P. J.; REEDY, S. E.; TUDOR, L. R.; DUBOVI, E. J.; VICKERS, M. L.; SELLS, S.; BALASURIYA, U. B. R. Development and Evaluation of One-Step TaqMan Real-Time Reverse Transcription-PCR Assays Targeting Nucleoprotein, Matrix, and Hemagglutinin Genes of Equine Influenza Virus. Journal of Clinical Microbiology, v.47, n.12, p.3907-3913, 2009.MACLACHLAN, N. J.; DUBOVI, E. J. Orthomyxoviridae. In.: Fenner's Veterinary Virology, London-UK: Elsevier, 4ed., 2011. p.356.

MANCINI, D.A.P.; CUNHA, E.M.S; LARA, M.C.C.S.H.; MENDONÇA, R.M.Z.; DIAS, A.L.F., CASTRO, A.F.; PINTO, J.R.; MENDONÇA, R.Z. Evidence of humanequine interspecies influenza vírus transmission. Virus Revue Research, v.11, n.1/2, p.44-50, 2006.

MORI, E.; FERREIRA, H. L.; FLORES, E.F. Orthomyxoviridaes. In.: FLORES, E. F. (org.).

Virologia Veterinária: virologia geral e doenças víricas. Santa Maria: Editora UFMS, p. 831896, 2012.

MUNFORD, J. A. Equine influenza. In COETZER, J.A. W.; THOMSON, G. R.; TUSTIN, R. C. Infectious Diseases of Livestock, Cape Town: Oxford University Press, p.854-859, 1994.

MYERS, C.; WILSON, W. D. Equine Influenza Virus. Clinical Techniques in Equine Practice, v.5, p.187-196, 2006.

NEWTON, R.; COOKE, A.; ELTON, D.; BRYANT, N.; RASH, A.; BOWMAN, S.; BLUNDEN, T.; MILLER, J.; HAMMOND, T. A.; COMM, I.; DALY, J. Canine influenza virus: cross-species transmission from horses. Veterinary Records, v.161, p.142-143, 2007.

OIE - World Organization for Animal Health. Equine Influenza. In.: Manual of Diagnostic Tests and Vaccines for Terrestrial Animals, p.5-6, 2012. Disponível em:

http://www.oie.int/fileadmin/Home/eng/Health_standards/tahm/2.05.07_EQ_INF.pdf. Acesso em: 17 out. 2012.

OIE - World Organization for Animal Health. Animal Health Information - Disease Information: Disease distribution maps. Disponível em:

http://www.oie.int/wahis_2/public/wahid.php/Diseaseinformation/Diseasedistributionmap.

Acesso em: 15 out. 2012. 
OLIVEIRA, G. S.; SCHIAVO, P. A.; MUZUR, C.; ANDRADE, C.M. Prevalência de anticorpos para o vírus da Influenza Equina, subtipo H3N8, em eqüídeos apreendidos no Estado do Rio de Janeiro. Ciência Rural. Santa Maria. v35, n.5, p.1213-1215, SET-OUT, 2005.

QUINLIVAN, M.; CULLINANE, A.; NELLY, M. VAN MAANEN, K.; HELDENS, J.; ARKINS, S. Comparison of Sensitivities of Virus Isolation, Antigen Detection, and Nucleic Acid Amplification for Detection of Equine Influenza Virus. Journal of Clinical Microbiology, v.42, n.2, p.759-763, 2004.QUINN, P. J. Microbiologia veterinária e doenças infecciosas. Porto Alegre: Artmed, 2005-2007. 512 p.

TIMONEY, P.J. Equine influenza. Comparative Immunology and Microbiology of Infectious Disease. v.19 n. 3, p.205-211, 1996.

TUMOVA, B. Equine Influenza: a segment in influenza virus ecology. Comp. Immunol. Microbiol. Infect. Dis., v. 3, p. 45-59, 1980.

WILSON, D.W. Equine influenza. In: TRAUB-DARGATZ, J.L. The Veterinary Clinics of North America: Equine Practice. London: Saunders, 1993. V.9, p.257-282.

YAMANAKA, T.; NEMOTO, M.; BANNAI, H.; TSUJIMURA, K.; KONDO, T.; MATSUMURA T.; MURANAKA, M.; UENO, T.; KINOSHITA, Y.; NIWA, H.; HIDARI, K. I. P. J.; SUZUKI, T. No evidence of horizontal infection in horses kept in close contact with dogs experimentally infected with canine influenza A virus (H3N8). Acta Veterinaria Scandinavica, v.54, n.25, p.1-5, 2012. 